http://rev.med.panacea.unica.edu.pe

Rev.méd.panacea 2013; 3(2): 58

Recibido: 06 de Julio del 2013 | Aceptado: 20 de Julio del 2013 | Publicado: 31 de Agosto del 2013

CONFICTO DE INTERES: NO DECLARADOS

CARTA AL EDITOR

\title{
SOCEMI: 20 años fomentando la investigación médica en pregrado
}

\section{SOCEMI: 20 YEARS ENCOURAGING UNDERGRADUATE MEDICAL RESEARCH}

Tania Acevedo-Villar, ${ }^{1,2, a}$

\author{
Facultad de Medicina, Universidad Nacional San Luis Gonzaga. Ica, Perú1 \\ Sociedad Científica de Estudiantes de Medicina de Ica (SOCEMI) ${ }^{2}$ \\ Estudiante de medicina ${ }^{a}$ \\ Sr. Editor.
}

iendo la investigación una herramienta básica en la solución de problemas, existe preocupación en las instituciones dedicadas a la salud por el escaso número de médicos investigadores, la poca producción científica y baja tasa de publicación (1). A manera de respuesta, las sociedades científicas cumplen un rol de promoción y capacitación de sus miembros en el quehacer científico. En el pregrado médico, tenemos las Sociedades Científicas de Estudiantes de Medicina (SOCIEM) conformadas por estudiantes de medicina que persiguen el fin de realizar trabajos de investigación y otros procesos relacionados a comunicar sus hallazgos (2) (3), en la búsqueda propia de una formación más integral para su futuro profesional. En el Perú, la Sociedad Científico Médico Estudiantil Peruana (SOCIMEP) reúne a las sociedades científicas de las Facultades de Medicina de todo el país.

La Sociedad Científica de Estudiantes de Medicina de Ica (SOCEMI) es una institución reconocida legalmente, conformada por estudiantes de Medicina Humana de la Facultad de Medicina "Daniel Alcides Carrión" (FMH-DAC) de la "Universidad Nacional San Luis Gonzaga de Ica”, creada con la finalidad de promover la capacitación y producción científica. Desde hace más de 20 años, ha desarrollado actividades de índole académico-científico y de proyección a la comunidad además de ser partícipe en eventos científicos regionales, nacionales e internacionales, dando a conocer su labor en la investigación. En sus años de existencia, ha consolidado los objetivos de fomentar ciencia, investigación y educación en los estudiantes de medicina de Ica, además del aporte a la publicación científica de la región Ica (4). Es una institución con participación activa en cada una de las ediciones del Congreso Científico Nacional de Estudiantes de Medicina (CCN), máximo evento de SOCIMEP con un total de 95 trabajos presentados durante el período 1993-2010 (5).

En su existencia, la Sociedad ha cosechado una gran cantidad de logros a nivel nacional e internacional, destacándose los logros a nivel internacional como el obtenido en el "IX Congreso Científico Internacional (CCI) de la Federación Latinoamericana de Sociedades Científicas de Estudiantes de Medicina (FELSOCEM), Guanajuato-México, 1994”, "XXIII CCI FELSOCEM Iquique-Chile 2008" y el más reciente obtenido durante el "XXVIII CCI FELSOCEM Honduras 2013" (6), obteniéndose el primer lugar en dichos eventos. Además de ser casa y organizador de eventos científicos como el "III Congreso Nacional de Estudiantes de Medicina (1989)" y organizador de la “Jornada Científica Regional Centro" en 4 oportunidades (6). Por lo mencionado anteriormente, es importante destacar la labor realizada por la SOCEMI durante sus primeros 20 años de existencia, destacándose no sólo por los logros ya mencionados, debiéndole agregarse a ello que es una institución tradicional de la FMH-DAC que sirve además como punto de encuentro de estudiantes de los diferentes años, lugar donde se desarrolla la amistad, compañerismo y hermandad. Se proyecta años con toma de nuevo retos y mayores responsabilidades tales como incrementar la producción científica de los estudiantes de la FMH-DAC y contribuir con la mejora de salud de Ica y del país a través de la investigación.

Autor Corresponsal: Tania Acevedo Villar. Telefono: (051)942433952. Direccion: Calle los Pacaes B-14. Ica, Perú. Correo electronico: tania.acevedo5@gmail.com.

\section{REFERENCIAS BIBLIOGRÁFICAS}

1. Salas S, Rigotti A. Médicos-Científicos en Chile: ¿Una especie en extinción? Rev Méd Chile. 2005; 133: 121-128

2. Arroyo-Hernández $\mathrm{H}$, De la Cruz W., Miranda-Soberón U. Dificultades para el desarrollo de investigaciones en pregrado en una universidad pública de provincia, Perú. Rev Peru Med Exp Salud Publica.2008; 25(4)

3. Molina-Ordóñez J, Huamaní C, MaytaTristán P. Apreciación estudiantil sobre la capacitación universitaria en Investigación: estudio preliminar. Rev Peru Med Exp Salud Pública. 2008; 25(3): 325-29.

4. Arroyo-Hernández $\mathrm{H}$, Zukerán-Medina $\mathrm{B}$, Miranda-Soberón U. Análisis bibliométrico de la producción científica biomédica en la región Ica, Perú. 1998-2010.Rev Méd Panacea. 2011; 1(1):2-8.

5. Alarco JJ, Álvarez-Andrade EV. Nuestra participación en los congresos científicos nacionales de estudiantes de medicina, 1993-2010.Rev.méd. panacea.2011; 1 (1):2223

6. SOCIPEM. Memorias SOCIPEM (Internet) (Consultado: 10 de Mayo 2013)

\section{CITA SUGERIDA.}

Acevedo-Villar T. SOCEMI: 20 años fomentando la investigación médica en pregrado. Rev méd panacea.2013; $3(2): 58$. 